\title{
Mamíferos como reservatórios de Trypanosoma sp. - Uma abordagem bibliométrica
}

\author{
Mammals as reservoirs of Trypanosoma sp. - A bibliometric approach \\ Mamíferos como reservorios de Trypanosoma sp. - Um enfoque bibliométrico
}

Recebido: 26/05/2021 | Revisado: 01/06/2021 | Aceito: 03/06/2021 | Publicado: 18/06/2021

\author{
Joselaine Souto Hall Silva \\ ORCID: https://orcid.org/0000-0001-5667-8871 \\ Universidade do Estado de Mato Grosso, Brasil \\ E-mail: joselaineshs@unemat.br \\ Dionei José da Silva \\ ORCID: https://orcid.org/0000-0002-6189-9756 \\ Universidade do Estado de Mato Grosso, Brasil \\ E-mail: dioneijs@unemat.br \\ Antonio Francisco Malheiros \\ ORCID: https://orcid.org/0000-0001-8169-0557 \\ Universidade do Estado de Mato Grosso, Brasil \\ E-mail: malheiros@unemat.br
}

\begin{abstract}
Resumo
As Doenças causadas por patógenos silvestres aos seres humanos constituem uma importante preocupação para os sistemas de saúde, principalmente na atualidade. Assim, compreender o ciclo dos patógenos nos hospedeiros e reservatórios é um passo no combate e controle destas doenças. Muitos animais silvestres, e dentre eles os mamíferos são importantes nos ciclos de várias doenças parasitárias como as tripanossomíases e vêm sendo estudadas por pesquisadores de todo o mundo. A fim de compreender a rede de pesquisas nessa temática, mamíferos como reservatórios de Trypanosoma, realizamos um estudo bibliométrico avaliando o conjunto de publicações sobre o tema no período de 2010 a 2020. Neste trabalho foram utilizadas publicações indexadas nas bases Web of Science e Scopus. Foram levantados 446 artigos e destes selecionados 97 que abordam objetivamente o tema pesquisado. Com base nesses artigos, foram identificados os principais periódicos que publicaram sobre o tema e temporalidade das publicações, bem como a origem dos animais estudados. Utilizando-se de ferramentas de análise bibliométrica foram elaborados mapas de relacionamento de Instituições de vínculo dos autores e redes de coautores, citações, cocitações, acoplamento bibliográfico e coocorrência de palavras-chave. Desta forma foi possível caracterizar como se estrutura o arcabouço das investigações a respeito de mamíferos como reservatórios de Trypanosoma, em todo o mundo.
\end{abstract}

Palavras-chave: Bibliometria; Parasita; Hospedeiro; Tripanossomíase.

\begin{abstract}
Diseases caused by wild pathogens to humans are an important concern for health systems, especially today. Thus, understanding the cycle of pathogens in hosts and reservoirs is a step-in combating and controlling these diseases. Many wild animals, including mammals, are important in the cycles of various parasitic diseases such as trypanosomiasis and have been studied by researchers around the world. To understand the research network on this subject, mammals as reservoirs of Trypanosoma, we carried out a bibliometric study evaluating the set of publications on the subject from 2010 to 2020. In this work, publications indexed in the Web of Science and Scopus databases were used. 446 articles were collected and 97 of these were selected, which objectively address the researched topic. Based on these articles, the main journals that published on the topic and timing of publications were identified, as well as the origin of the animals studied. Using bibliometric analysis tools, relationship maps of Institutions linked to the authors and networks of co-authors, citations, co-citations, bibliographic coupling, and co-occurrence of keywords were elaborated. In this way, it was possible to characterize how the framework of investigations about mammals as reservoirs of Trypanosoma is structured around the world.
\end{abstract}

Keywords: Bibliometry; Parasite; Host; Trypanosomiasis.

\section{Resumen}

Las enfermedades causadas por patógenos silvestres a los seres humanos son una preocupación importante para los sistemas de salud, especialmente en la actualidad. Por lo tanto, comprender el ciclo de patógenos en huéspedes y reservorios es un paso para combatir y controlar estas enfermedades. Muchos animales salvajes, incluidos los mamíferos, son importantes en los ciclos de diversas enfermedades parasitarias como la tripanosomiasis y han sido estudiados por investigadores de todo el mundo. Para comprender la red de investigación sobre esta temática, mamíferos como reservorios de Trypanosoma. Realizamos un estudio bibliométrico evaluando el conjunto de publicaciones sobre el tema desde 2010 hasta 2020. En este trabajo se utilizaron publicaciones indexadas en las bases de datos Web of Science y Scopus. Se recopilaron 446 artículos de los cuales se seleccionaron 97, que abordan 
objetivamente el tema investigado. A partir de estos artículos se identificaron las principales revistas que publicaron sobre el tema y el momento de las publicaciones, así como el origen de los animales estudiados. Mediante herramientas de análisis bibliométrico se elaboraron mapas de relación de Instituciones vinculadas a los autores y redes de coautores, citaciones, cocitaciones, acoplamiento bibliográfico y coocurrencia de palabras clave. De esta forma, fue posible caracterizar cómo se estructura el marco de las investigaciones en torno a los mamíferos como reservorios de Trypanosoma, a nivel mundial.

Palabras clave: Bibliometría; Parásito; Anfitrión; Tripanosomiasis.

\section{Introdução}

A relação parasito-hospedeiro se estabeleceu por processos adaptativos e de coevolução ocorrido ao longo de milhares de anos. Esta é uma relação ecológica de benefício unilateral para o parasito que embora possa trazer prejuízo ao hospedeiro, não lhe interessa a morte deste último (Neves, 2005). Ao longo deste processo evolutivo diversos animais, e dentre eles os mamíferos, tornaram hospedeiros de ampla diversidade de parasitos (Santos, et al., 2015). Na maioria das vezes esta relação não resulta em doenças, e o hospedeiro pode se tornar um hospedeiro intermediário ou reservatório do parasito. No entanto em alguns casos o parasito pode causar sérios danos ao hospedeiro (Araújo, et al., 2013).

O ser humano também faz parte deste ciclo e desde a condição de pré-hominídeos vem carregando e compartilhando parasitos (Araújo, et al., 2013). Esta relação entre doenças parasitárias, humanos, hospedeiros e reservatórios é mencionada deste o século XV a. C. e pelos orientais ao relacionar a presença de ratos e peste bubônica, bem como pelos egípcios que conheciam o ciclo de vários helmintos (Ávila-Pires, 1989). Embora as preocupações com esta relação parasito e hospedeiro existam desde tempos remotos, estudos com enfoques ecológicos sobre reservatórios de doenças por animais não humanos só se desenvolveram no século 20 (Ávila-Pires, 1989). A partir de então, as pesquisas têm apontado para a importância de se valorizar o estudo da ecologia dos reservatórios naturais como meio de se compreender o ciclo de transmissão de doenças, as relações parasito-hospedeiro e os mecanismos de seu controle (Roque, 2009).

Neste cenário, desde os primeiros estudos sobre a doença de Chagas em humanos em 1909 por Carlos Chagas, abriuse o interesse pela investigação não só sobre o Trypanosoma cruzi e a doença de chagas, mas sobre as várias espécies de Trypanosoma, seus possíveis reservatórios, os vetores e as doenças ocasionadas (Malafaia \& Rodrigues, 2010). Desde então, estudos tem investigado mamíferos silvestres e domésticos como potenciais reservatórios deste grupo de parasitos, principalmente Trypanosoma cruzi (Neves, 2005; Jansen, et al., 2020).

A melhor compreensão do ciclo das doenças parasitárias, se dá na medida em que se compreende os aspectos ecológicos da doença, perpassando pela análise das condições da paisagem e processos de antropização (Alho, 2012; Huang, et al., 2016) bem como pela identificação dos hospedeiros/reservatórios. Diante desta premissa e entendendo que estudos têm buscado identificar os mamíferos que atuam como reservatórios de Trypanosoma, realizamos um estudo bibliométrico a fim de conhecer as principais pesquisas, pesquisadores, grupos de pesquisa, instituições e países que têm se dedicado a esta temática na última década.

Partimos do princípio de que estudos bibliométricos podem contribuir com a análise da produção científica de uma certa temática e identifica os principais atores e processos de produção de conhecimento na área em questão (Machado Junior, et al., 2016; Souza \& Fontenele, 2019). Técnicas bibliométricas, por consistirem em métodos quantitativos (Araújo 2006) permitem mensurar o quanto determinada temática constitui um tópico recorrente de pesquisa (hot topic) demonstrando a importância e o empenho de cientistas em elucidar perguntas a tal respeito. A aplicação de tais técnicas, permite, por meio de indicadores, revelar os autores mais produtivos e influentes na temática em questão, bem como as principais instituições a que se vinculam e periódicos que mais divulgam o tema (Bufrem \& Prates, 2005; Lopes, et al., 2012). Portanto, pode-se dizer que por técnicas bibliométricas é possível identificar as tendências da produção científica, pesquisada, no cenário internacional.

Neste estudo aplicamos técnicas bibliométricas a fim compreender o cenário de pesquisas que aborda mamíferos 
como hospedeiro/reservatório de Trypanosoma. Foram considerados estudos realizados em todo o mundo e publicados no período de 2010 a junho de 2020 e que se encontram indexados nas bases Web of Science (WoS) e Scopus. A WoS constitui uma das mais importantes bases de indexação multidisciplinar e por mais de 40 anos foi a maior base de indexação de dados bibliométricos, com mais de 13.000 periódicos indexados. A Scopus agrega desde 1996 um conjunto ainda mais vasto de periódicos, incluindo conteúdos de outras bases como da Elsevier, ampliando a cobertura de fontes de dados científicos com mais de 18.000 títulos de periódicos (Lopes, et al., 2012).

\section{Materiais e Métodos}

A investigação do presente estudo foi realizada sob forma exploratória e descritiva com abordagem quantitativa ao avaliar dados da produção científica como abordado por Wallin (2005) e Souza e Fontenele (2019). É uma pesquisa do tipo bibliométrica, conforme descrevem Cronin; Shaw e La Barre (2003) e Jarneving (2007) na medida em que se avaliou análises métricas relacionadas às fontes das publicações, países e instituições dos pesquisadores, análise de coautoria, cocitação, acoplamento bibliográfico e coocorrência de palavras-chave.

O conjunto de dados foi estruturado a partir da análise de artigos acessados por meio da base de dados disponíveis nas plataformas Web of Science (WoS) (<http://www. webofscience.com) e Scopus (<http://www.scopus.com), em 07 de julho de 2020. Nestas bases foram realizadas buscas visando encontrar artigos científicos indexados que retratam estudos sobre mamíferos como portadores de Trypanosoma.

Foram utilizados os termos de pesquisa, em inglês, Trypanosoma, mammals, reservoir, host, wild, domestic e sylvatic, que pudessem estar expressos no título, resumo e/ou nas palavras-chave. Os termos foram aplicados em diversas combinações, utilizando-se os operadores booleanos AND e OR, assim como asterisco após cada um, com objetivo de serem encontrados no singular, plural e suas formas variantes (Figura 1). O filtro de tempo foi correspondente ao período de janeiro de 2010 a junho de 2020.

Figura 1. Modelos aplicados na busca dos artigos nas bases de dados Web of Science e Scopus.

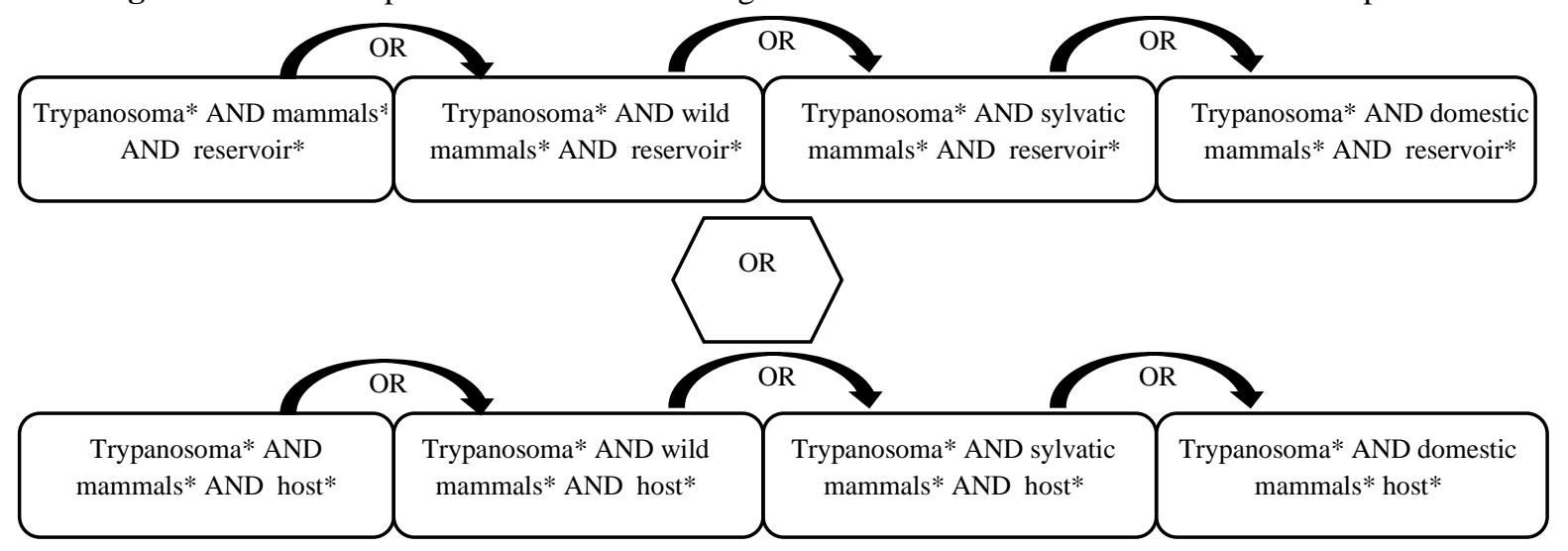

Fonte: Autores.

Optou-se pela busca nas bases Web of Science e Scopus devido à ampla abrangência de ambas as bases com indexação de mais de 20.000 periódicos. Considerou-se também a possibilidade da extração das métricas relativas a cada publicação bem como a compatibilidade da extração das informações para análise em outros softwares como VOSviewer 1.6.16 (Eck \& Waltman, 2010) e Ucinet 6.721 (Borgatti, et al., 2002). 
Após obter a lista dos artigos publicados, que reportavam os termos da pesquisa, foi realizada uma triagem para identificar e fazer a retirada das publicações repetidas, em ambas as bases. Os artigos que apresentaram uma ou mais palavras pesquisadas, mas não continham dados com focos na pesquisa, foram considerados genéricos e excluídos da análise.

A partir de então, cada registro foi examinado para observar se estava relacionado com o foco da pesquisa e que permitisse a exploração de indicadores. Um pesquisador independente também fez a revisão dos conteúdos dos artigos a fim de garantir que todos os conteúdos de interesse, e somente estes, estivessem inclusos na revisão. Primeiramente foram considerados os aspectos relativos à produção científica relacionado ao tema, como: a) Tendência temporal para a produção científica do tema abordado; b) quais os principais periódicos que publicaram informações científicas sobre a temática pesquisada; c) a nacionalidade das instituições de vínculo dos pesquisadores constantes nos artigos; d) a participação de cada pesquisador nos artigos; e) qual a contribuição de cada país para esta abordagem de pesquisa; f) quais os autores e estudos mais citados e cocitados.

Para analisar a tendência e número de publicações em função da escala temporal dos anos foi analisado por regressão polinomial, pelo software Systat (Wilkinson, 1998), buscando diagnosticar se o tema pesquisado apresentou tendência de crescimento ou estabilidade, o que indica ser uma temática de interesse atual da ciência - hot topic. Considerou o valor significativo quanto $\mathrm{p} \leq 0,05$. Considerando que o levantamento dos artigos de 2020 abrange somente até o mês de junho, este ano não entrou nesta análise.

As métricas iniciais foram obtidas por meio dos links de análises em ambas as bases e os dados exportados em formatos analisáveis em extensão "ciw", compatível com VOSviewer e "xls" com software Microssoft Excel ${ }^{\circledR}$, (2010). O mapa de distribuição do local das pesquisas constantes nos artigos foi elaborado com base nos dados da origem dos mamíferos estudados. Para a origem dos autores foram consideradas as instituições às quais estão vinculados.

As redes de relacionamento com respectivos mapas foram elaboradas com base nas informações dos arquivos exportados das bases de dados e construídas por meio do software VOSviewer (Eck \& Waltman, 2010). Os arquivos oriundos das bases de indexação foram gerados em 02 de abril de 2021. Desta forma os relacionamentos gerados correspondem às interações registradas nas bases até esta data. Para analisar a estrutura da rede foram utilizados os graus de centralidade e intermediação. O grau de centralidade leva em consideração todos os caminhos da rede e as conexões diretas de um nó com os outros, mostrando a relevância dos autores no contexto da rede (Oliveira \& Grácio, 2012; Carvalho, et al., 2013). Assim quanto maior o grau de centralidade, maior o número de conexões diretas de um nó com os outros elementos da rede.

O grau de intermediação está relacionado aos nós que ficam entre dois outros nós da rede estabelecendo a intermediação entre eles, constituindo o caminho mais curto de conexão entre os nós. Desta forma, quanto maior o grau de intermediação, maior será o poder de intermediação de um nó da rede (Chen, 2013; Carvalho, et al., 2013). As métricas de centralidade e de intermediação foram obtidas a partir de arquivo Pajek gerado pelo VOSviewer e analisadas no software Ucinet.

Considerando que há variação na forma de citação dos autores e da instituição em cada revista, o arquivo "ciw" gerado foi aberto em "txt" e realizado a padronização dos nomes dos autores e instituições de vínculo. Desta forma possibilitou-se que cada autor e instituição aparecesse uma única vez nas redes.

\section{Resultados}

Foram compiladas 446 publicações nos termos de buscas pré-definidos, dos quais 210 listados na base Scopus e 236 na base Web of Science. Após comparação de títulos e autores foi observado 142 publicações listadas em ambas as bases, que foram mantidas uma única vez, restando então 294 artigos. Destas, 197 publicações não foram pertinentes ao enfoque da pesquisa e após refinamento foram excluídas, restando ao final 97 artigos que atenderam aos critérios de inclusão deste estudo. 
Apenas três dos artigos selecionados se encontravam indexados exclusivamente na base Scopus, todos os demais foram registrados em ambas as bases (Figura 2).

Figura 2. Fluxograma referente à busca e seleção dos artigos avaliados no estudo

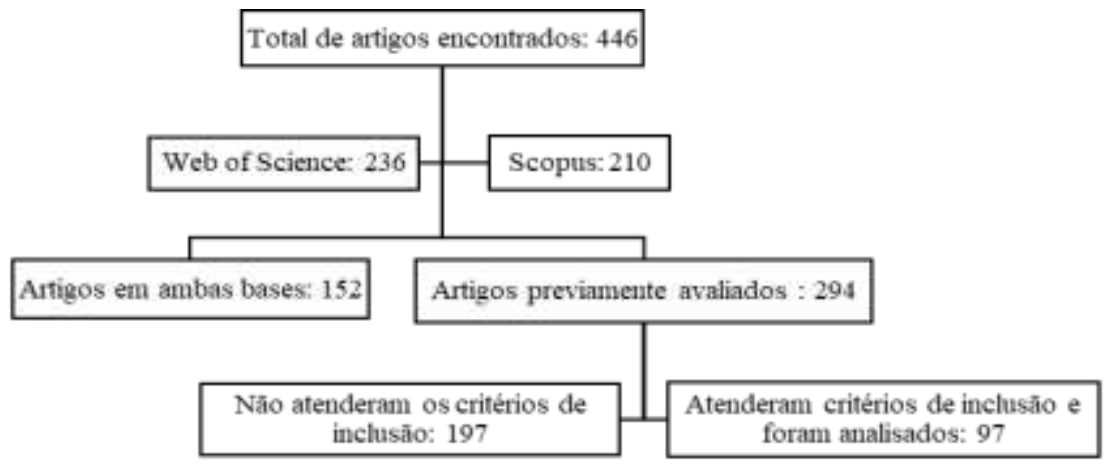

Fonte: Autores.

\subsection{Periódicos e temporalidade das publicações}

Os 97 artigos analisados foram publicados, essencialmente na língua inglesa (97\%) em 38 revistas distintas, dentre as quais um conjunto de sete revistas (Acta Tropica, Vector borne and Zoonotic Diseases, Parasites \& Vectors, Veterinary Parasitology, Parasitology, Plos One e Memórias do Instituto Oswaldo Cruz) foram responsáveis por 54,6\% das publicações (Figura 3).

Figura 3. Demonstrativo da concentração da publicação de artigos com enfoque em mamíferos como reservatórios de Trypanosoma, por revista, no período de 2010 a junho de 2020.

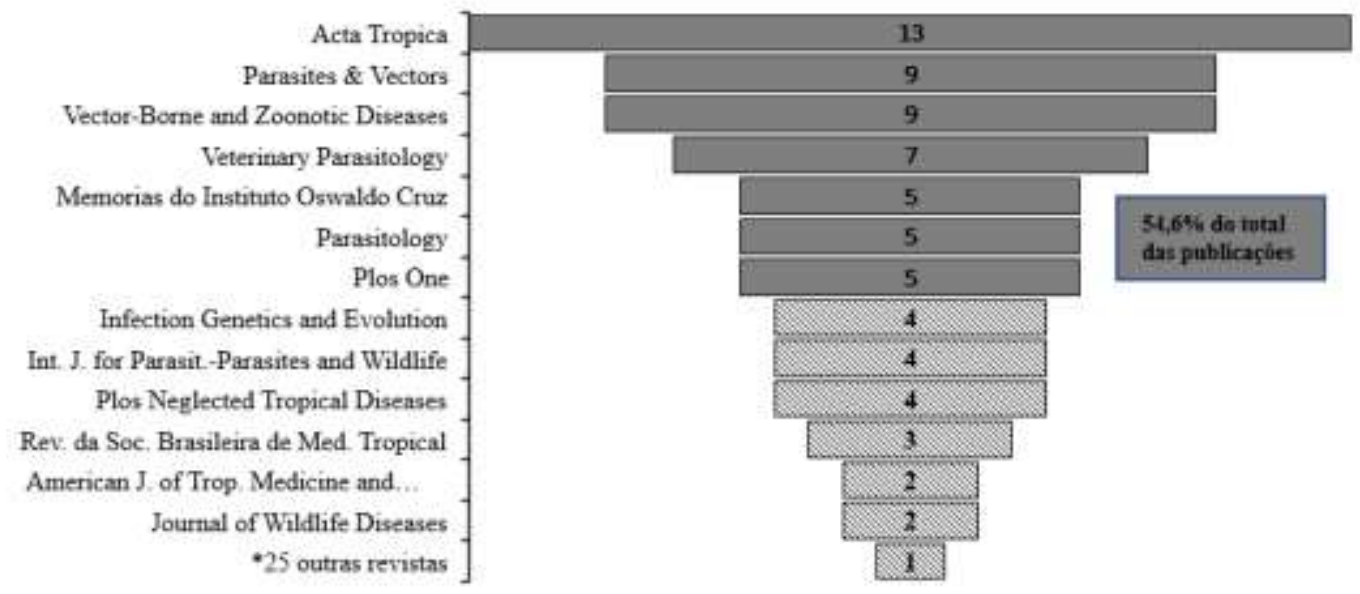

\footnotetext{
* American Journal of Primatology; Austral Journal of Veterinary Sciences; Biomedica; Biomed Research International; Cadernos de Saúde Pública; Ecohealth; Ecological Applications; Experimental Parasitology; International Journal for Parasitology; Journal of Infectious Diseases; Journal of Infection and Public Health; Journal of Medical Entomology; Molecular Ecology; Medical and Veterinary Entomology; Parasitology Research; Proceedings of The Royal Society B; Revista Argentina de Microbiologia; Revista Cientifica-Facultad de Ciencias Veterinarias; Semina-Ciencias Agrarias; Science of Nature; Tropical and Subtropical Agroecosystems; Transactions of the Royal Society of Tropical Medicine and Hygiene; Veterinary Medicine International; Veterinary Medicine and Science; Wildlife Society Bulletin. Fonte: Autores.
}

A análise da rede de relacionamento entre as revistas e respectivas citações mostra pelo tamanho dos círculos a proporção quantitativa de citações recebidas e as linhas a interação de citações com respectiva intensidade. As revistas Acta Trópica, Parasites \& Vectors e Plos One são as que apresentam maior grau de centralidade $(0.204 ; 0.157 ; 0.133)$ enquanto a 
Vector Borne and Zoonotic Diseases, Plos One e Parasitology são as com maior grau de intermediação $(19.753 ; 16.109 ; 8.755)$ (Figura 4).

Figura 4. Rede de interações entre as revistas e respectivas citações, elaborada no software de visualização VOSviewer a partir de dados bibliométricos extraídos de 97 artigos revisados, com a temática mamíferos como reservatórios de Trypanosoma, e indexados na Web of Science e Scopus. Utilizou-se como tipo de análise citação e método de contagem revista de origem.

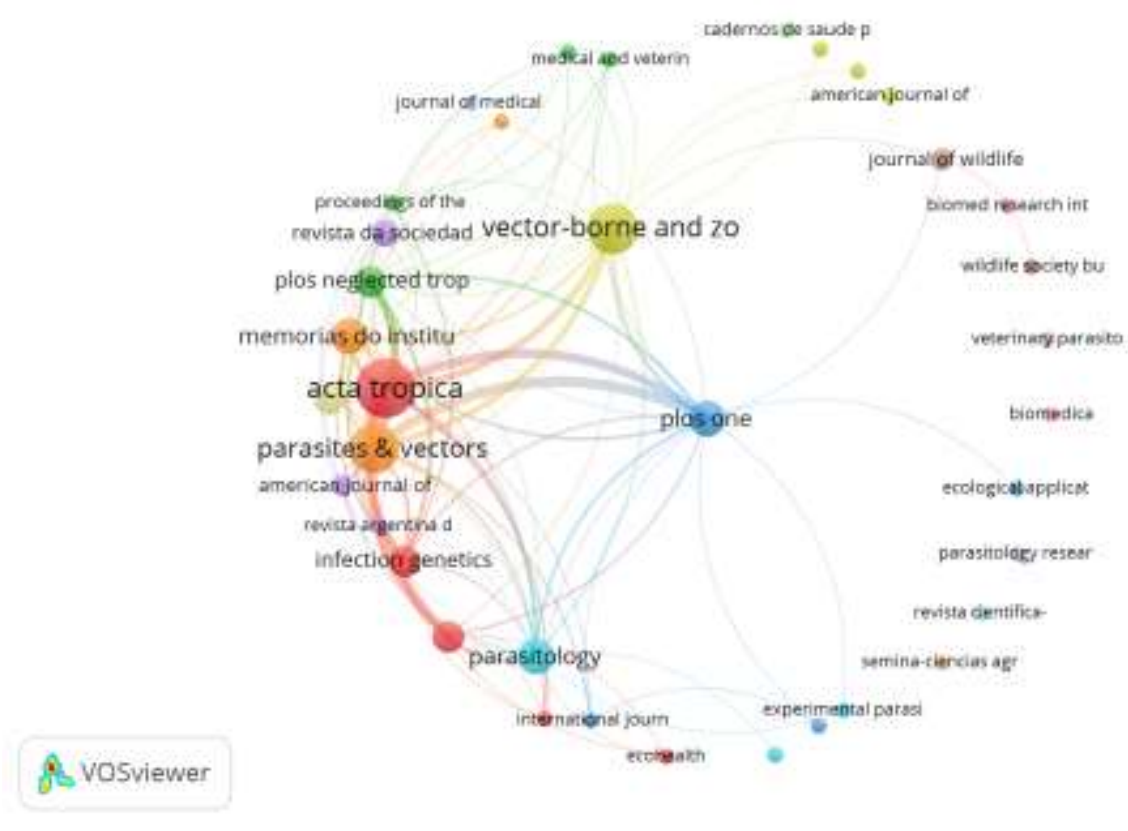

Fonte: Autores.

A maioria dos artigos (54\%) foram caracterizados pelas bases de indexação na área de Parasitologia, seguidos por Medicina tropical (40,4\%); Doenças Infeciosas (21\%), Saúde Pública Ambiental (15,9\%), Ciências Veterinárias (12,7 \%) e Ecologia (8,5\%). Outras 13 áreas são descritas em percentual inferior a 6,5\%. O total dos valores supera os $100 \%$, tendo em vista que um artigo pode ser considerado em mais de uma área.

O número de publicações variou de quatro a 13 ao longo dos 10 anos analisados $(\bar{x}=8,81 \pm 3,02)$ numa proporção média de 1,30 trabalhos por revista/ano $( \pm 0,32)$. A regressão polinomial mostra tendência crescente significativa $\left(R^{2}=0,748, p\right.$ $=0,003$ ) nas publicações ao longo dos anos com maior destaque para 2015 e 2019 (Figura 5). Com relação às revistas, com exceção da Acta Trópica que teve a concentração das publicações no período de 2010 a 2013, as demais seis revistas com maior número de publicações tiveram estas bem distribuídas ao longo dos anos. 
Figura 5. Regressão polinomial do número de publicações nas bases Web of Science e Scopus, de 2010 a 2019 , com enfoque em mamíferos como reservatórios de Trypanosoma.

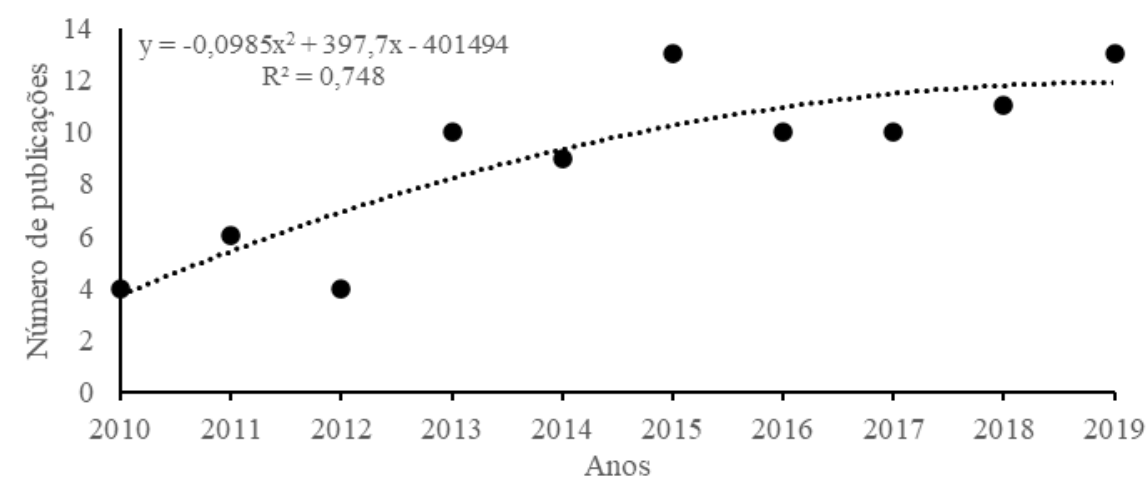

Fonte: Autores.

\subsection{Origem das fontes de pesquisa e pesquisadores}

Os artigos revisados reportam pesquisas realizadas principalmente com mamíferos originários da América do Sul $(n=75)$, com destaque para o Brasil $(n=39 ; 40,20 \%)$. Outras vinte $(20,61 \%)$ publicações tiveram como base análise de mamíferos coletados nos Estados Unidos e México e oito estudos foram realizados a partir de coletas em países da Ásia, Europa, África e Oceania (Figura 6). O total ultrapassa o valor de 97 visto que alguns estudos utilizaram dados de mais de um país.

Figura 6. Distribuição dos 97 estudos com referência a mamíferos como reservatórios de Trypanosoma, publicados no período de 2010 a junho de 2020, conforme origem dos mamíferos analisados.

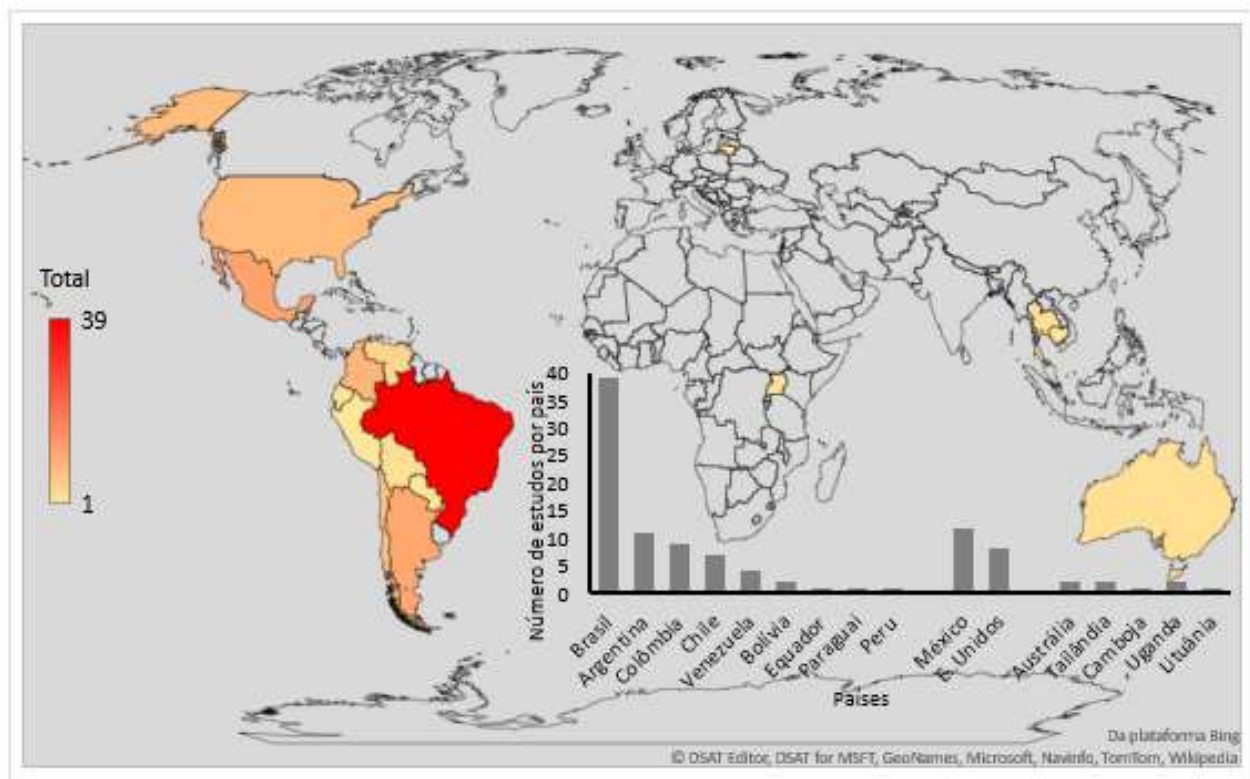

Fonte: Autores.

A rede de relacionamento construída entre autores e país de origem (Figura 7) mostra o vínculo com 27 países em oito clusters. O tamanho dos círculos reflete a quantidade de autores por país, as cores os relacionamentos em termos de grupo e as linhas com respectivas intensidades as interligações dos pesquisadores entre países. Assim o Brasil aparece como o país que concentra o maior número de autores integrantes dos 97 artigos analisados, bem como o maior grau de intermediação entre os 
países (51.205), seguido pelos Estados Unidos (16.333). Com relação à centralidade ocorre inversão de posição entre estes países onde os Estados Unidos é o país com maior grau de centralidade $(0,173)$ e o Brasil o segundo $(0,163)$. Venezuela e Lituânia não apresentaram relacionamentos com grupos de pesquisa de nenhum outro país.

Figura 7. Rede de relacionamentos de autores e países de origem, elaborado no software de visualização VOSviewer a partir de dados bibliométricos extraídos de 97 artigos revisados, com a temática mamíferos como reservatórios de Trypanosoma, e indexados na Web of Science e Scopus. Utilizou-se como tipo de análise autores e método de contagem países.

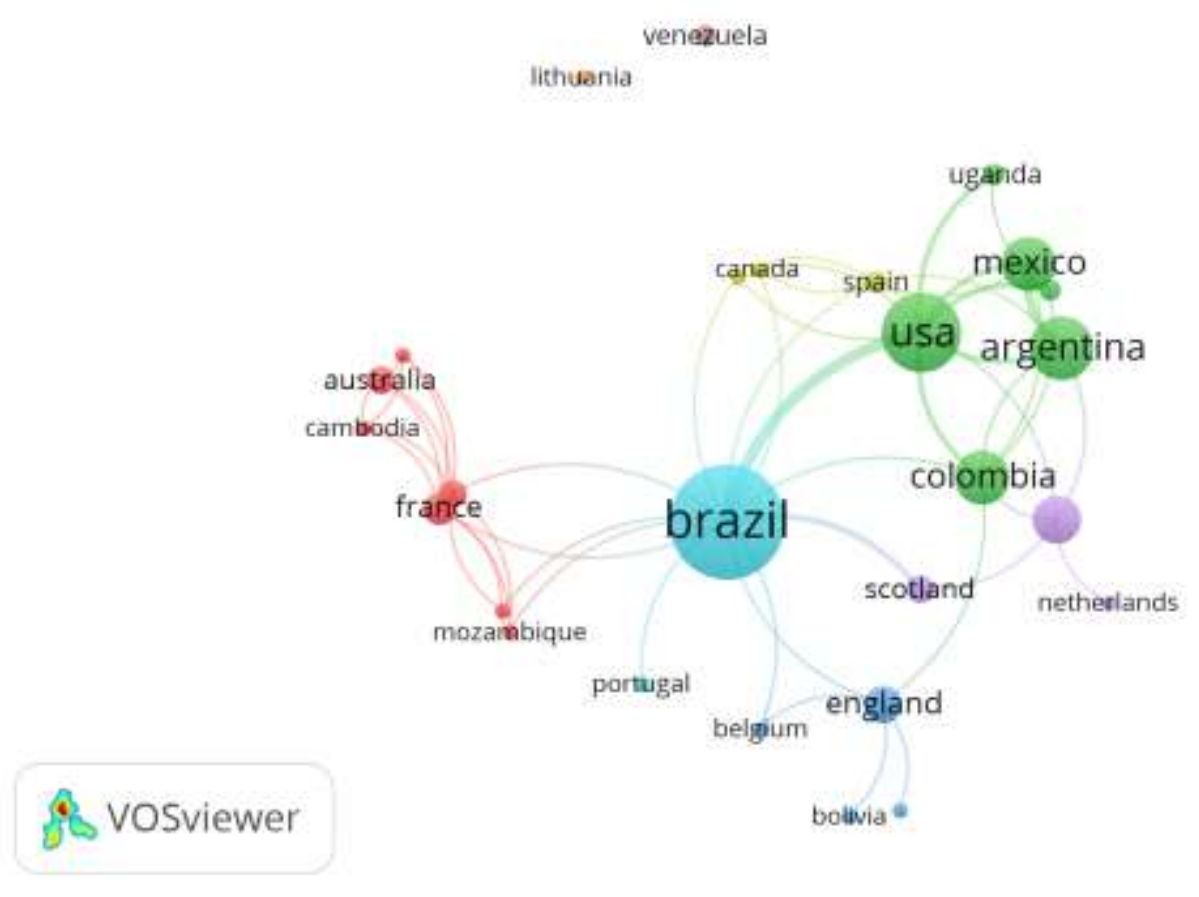

Fonte: Autores.

\subsection{Instituições de vínculo dos autores}

Foram identificados vínculos dos autores com 170 instituições de pesquisa. Dos 97 artigos analisados, 38,14\% tiveram seu desenvolvimento vinculado à alguma instituição brasileira, sendo 20,62\% relacionados à Fundação Oswaldo Cruz, seguida pela Universidade de São Paulo. Estas instituições também apresentaram os maiores graus de centralidade (0.054 e 0.033) e de intermediação (33.165 e 17.001) (S2 - Quadro 3). A rede de relacionamento entre instituições é apresentada na Figura 8, considerando as 44 instituições que tiveram pelo menos dois dos 97 artigos com autores a elas vinculados. O tamanho dos círculos se relaciona à quantidade de autores dos artigos vinculados a elas, as cores os relacionamentos em termos de grupo e as linhas com respectivas intensidades as interligações das instituições, por meio de seus pesquisadores. 
Figura 8. Rede de relacionamentos de autores e instituições de vínculo, elaborado no software VOSviewer a partir de dados bibliométricos extraídos de 97 artigos revisados, com a temática mamíferos como reservatórios de Trypanosoma, e indexados na Web of Science e Scopus. Utilizou-se como tipo de análise autores e método de contagem instituições de vínculo. Dentre as 170 instituições de vínculo foram considerados as 44 com pelo menos duas publicações, das 97, a elas vinculadas.

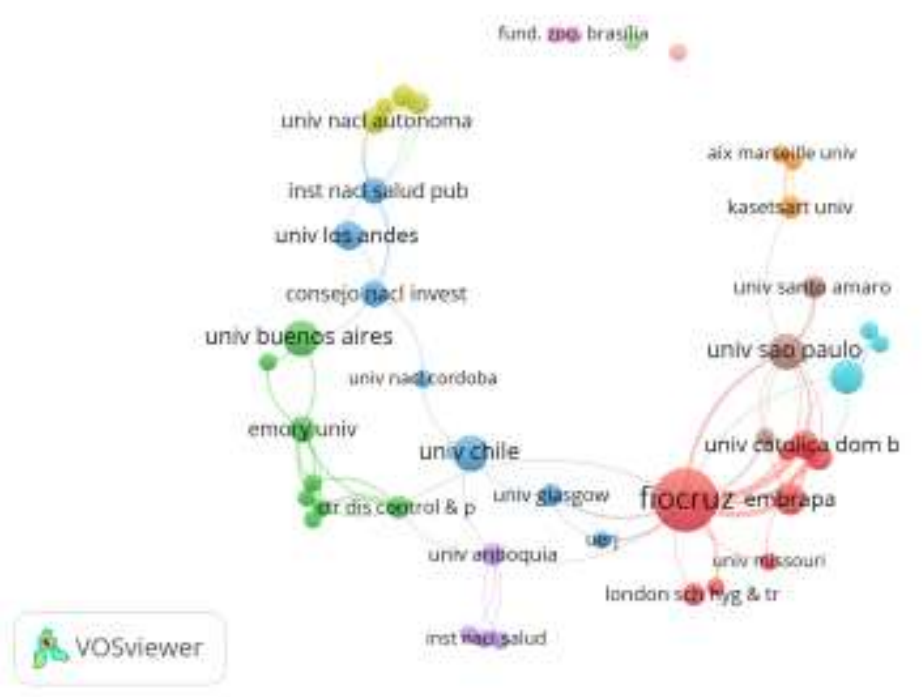

Fonte: Autores.

\subsection{Rede de coautores}

Os 97 artigos revisados tiveram a participação de 474 pesquisadores e nenhum deles teve autoria única. A Figura 9 representa as redes de relacionamento entre os autores dos artigos, considerando os 93 autores que participaram no mínimo em duas das 97 publicações. Foram identificados 15 clusters principais, demonstrado pelas cores e que representam os relacionamentos em termos de um grupo, os círculos representam os autores e o tamanho a quantidade de participação de cada autor nas publicações. 
Figura 9. Rede dos 93 autores participantes em no mínimo duas publicações analisadas no software VOSviewer a partir de dados bibliométricos extraídos de 97 artigos revisados, com a temática mamíferos como reservatórios de Trypanosoma, e indexados na Web of Science e Scopus. Utilizou-se como tipo de análise co-autorias e método de contagem autores.

\section{vosviewer}

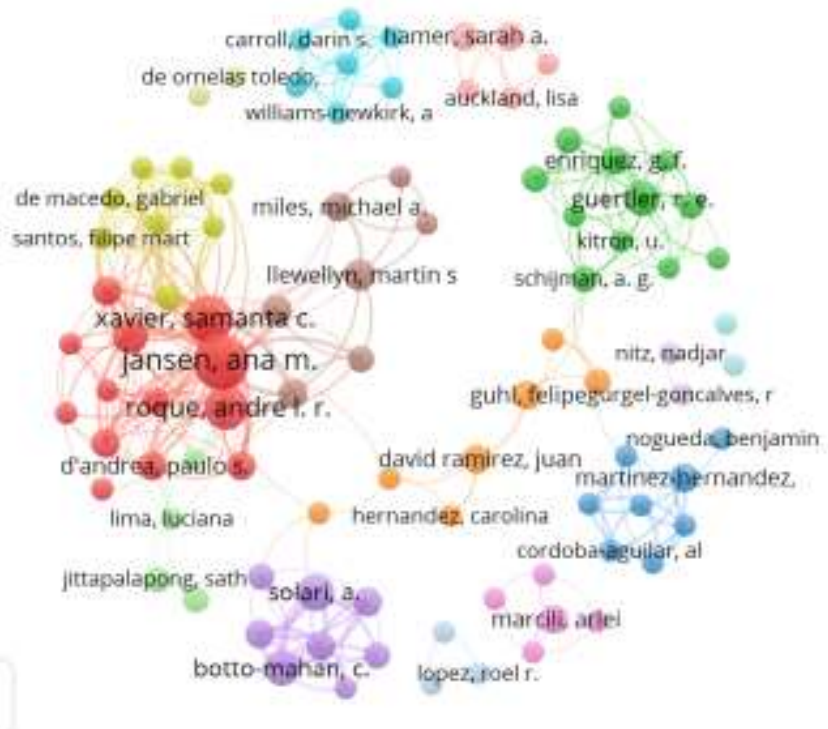

Fonte: Autores.

A pesquisadora Ana Maria Jansen foi a autora mais presente nos estudos, figurando em 24,74\% das publicações, seguida de outros dois pesquisadores, também brasileiros, Samanta Cristina Chagas Xavier, em 16,49\% e, André Luiz Rodrigues Roque, em 12,47\%. Estes autores aparecem no mesmo cluster, bem como são aqueles com maior grau de centralidade $(0.039 ; 0.027 ; 0.019)$. A métrica de intermediação também mostra maior grau para Jansen (62.054) seguida por Omar Cantillo-Barraza (45.873) e Juan David Ramirez (43.033).

\subsection{Rede de citações}

Dentre os 474 autores integrantes dos 97 artigos analisados, Ana Maria Jansen foi a mais citada, seguida por Samanta Cristina Chagas Xavier e André Luiz Rodrigues Roque apresentando os maiores graus de centralidade (0.029; 0.020; 0.017) e de intermediação $(11.641 ; 6.580 ; 5.670)$. O mapa da rede de relacionamento construído a partir da seleção de 93 autores participantes em pelo menos dois dos 97 artigos (Figura 10) mostra a formação de oito clusters retratado pelas cores cujos círculos representam os autores, o tamanho a proporção de citações e as linhas os relacionamentos de citações. 
Figura 10. Rede de relacionamentos de 93 principais autores, com pelo menos duas citações, elaborado no software de visualização VOSviewer a partir de dados bibliométricos extraídos de 97 artigos revisados, com a temática mamíferos como reservatórios de Trypanosoma, e indexados na Web of Science e Scopus. Utilizou-se como tipo de análise citações e método de contagem autores.

vosviewer

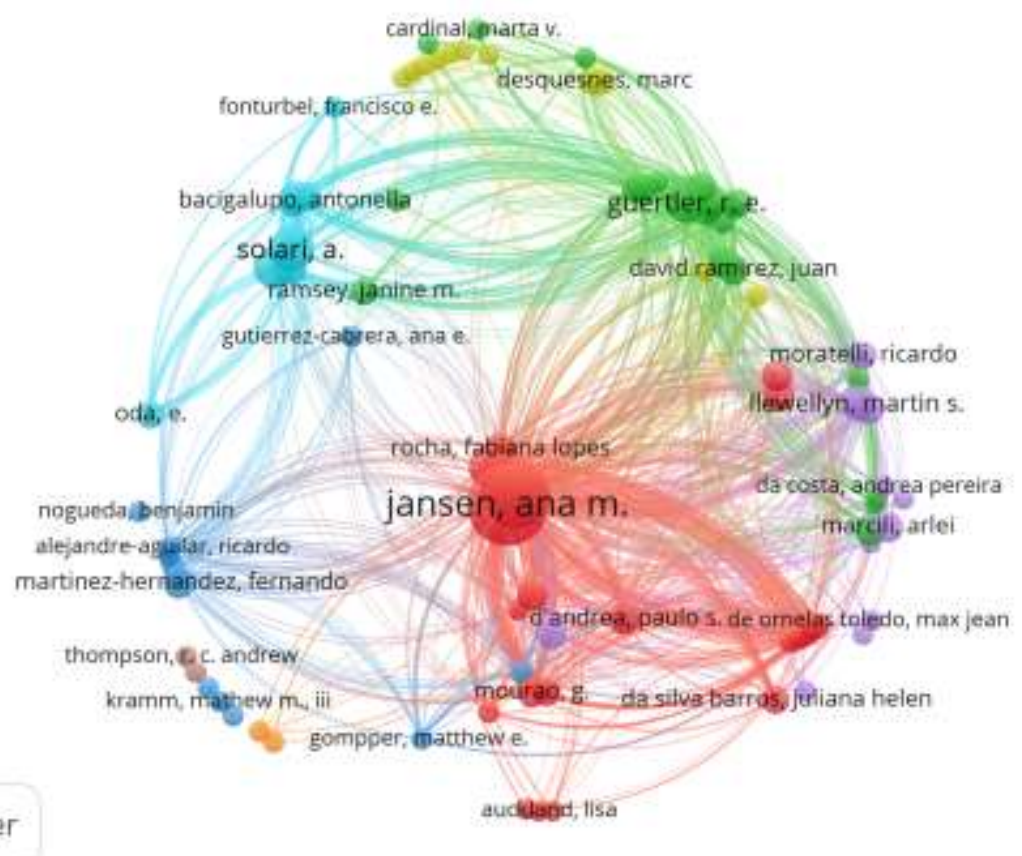

Fonte: Autores.

\subsection{Rede de cocitações}

Nos 97 artigos analisados foram encontrados 1.950 autores cocitados, com os quais foi estruturada uma rede de relacionamento considerando aqueles que foram cocitados em pelo menos 15 publicações dos estudos avaliados. Foram identificados 39 autores cocitados, agrupados em quatro clusters. Os círculos estão denominados pelo nome do primeiro autor, cuja cor e linhas representam os relacionamentos entre os autores (Figura 11). O tamanho dos círculos é proporcional ao número de citações que cada autor recebeu e neste caso há destaque para Zingales, B., seguido de Marcili, A.; Herrera, H. M.; Ramirez, J. D. e Jansen A. M. Quanto ao grau de centralidade Zingales e Marcili também se apresentam como os principais (0.424 e 0.371), no entanto Ramirez e Jansen apresentam maior grau (0.306; 0.300) do que Herrera que neste ranking encontrase em décimo primeiro lugar (0.0217). Quanto ao grau de intermediação 16 autores aparecem empatados (0.182). Dentre os cinco autores com maior número de citações e com maior grau de centralidade, apenas Jansen não aparecem entre os 16 com maior grau de intermediação, estando na vigésima sexta posição. 
Figura 11. Rede de relacionamentos dos 39 autores com maiores relacionamentos de cocitações, que aprecem citados em pelo menos 15 vezes dentre os 97 artigos analisados. O mapa foi elaborado no software de visualização VOSviewer a partir de dados bibliométricos extraídos de 97 artigos revisados, com a temática mamíferos como reservatórios de Trypanosoma, e indexados na Web of Science e Scopus. Utilizou-se como tipo de análise cocitação e método de contagem autores citados.

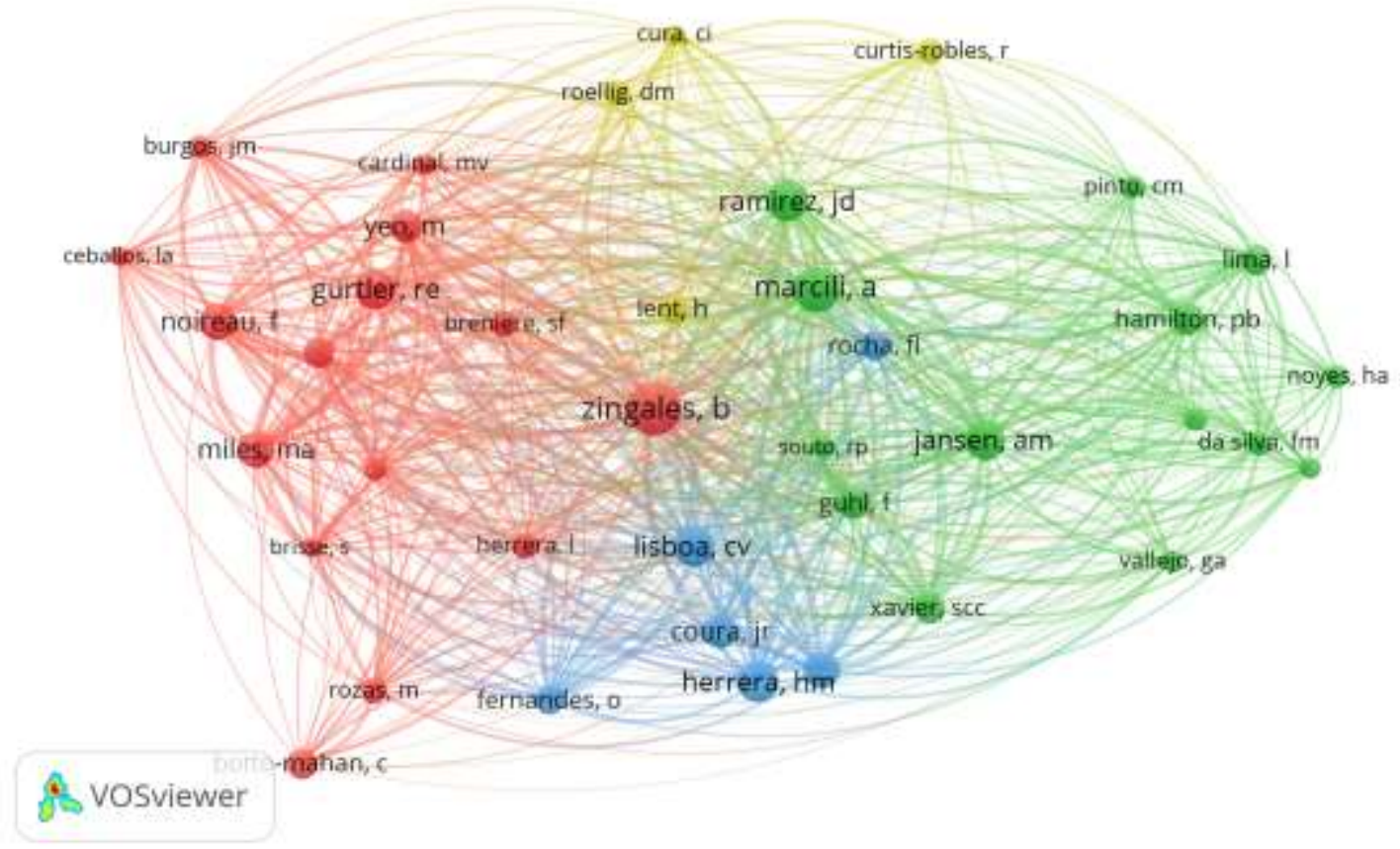

Fonte: Autores.

A rede de relacionamento levando em consideração a cocitação de referências bibliográficas, construída com base nas referências citadas no mínimo 15 vezes nos 97 artigos analisados, resultou numa rede com 28 artigos agrupados em quatro clusters indicado pelas cores. Os círculos estão nominados pelo primeiro autor da referência e o respectivo ano de publicação e o seu tamanho indica proporcionalmente o número de vezes que cada referência foi citada. A espessura das linhas representa a intensidade dos laços de cocitações (Figura 12).

Dois estudos liderados por Zingales são os mais cocitados. O primeiro publicado em 2011 (doi 10.1016/j.meegid.2011.12.009) é citado em 33\% dos 97 artigos analisados enquanto o segundo publicado em 2009 (doi 10.1590/s0074-02762009000700021) é citado em 30\% deles. Estes artigos também foram aqueles que apresentaram os maiores graus de centralidade $(0.473 ; 0.399)$, enquanto maior o grau de intermediação foi equivalente para 12 dos 28 artigos da rede. 
Figura 12. Rede de cocitações de referências citadas no mínimo em 10 dos 97 trabalhos analisados. O mapa foi elaborado no software de visualização VOSviewer a partir de dados bibliométricos extraídos de 97 artigos revisados, com a temática mamíferos como reservatórios de Trypanosoma, e indexados na Web of Science e Scopus. Utilizou-se como tipo de análise cocitação e método de contagem referência citada.

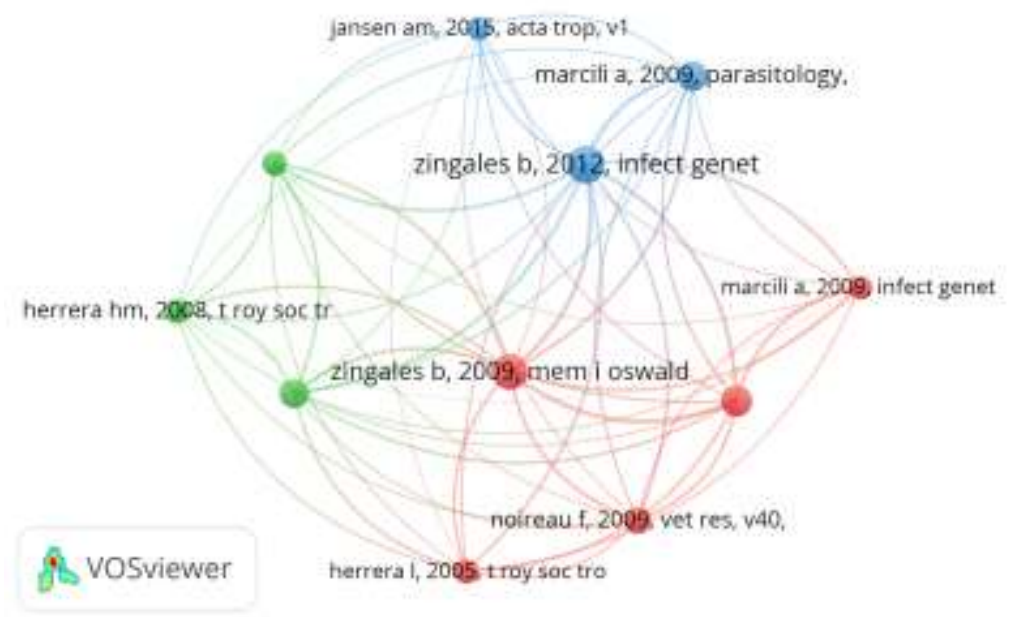

Fonte: Autores.

\subsection{Rede de acoplamento bibliográfico}

A rede de acoplamento bibliográfico foi elaborada considerando autores que participaram no mínimo em três dos 97 artigos analisados, gerando relação entre 37 autores agrupados em quatro clusters, demonstrado pelas cores. O agrupamento de autores, em um mesmo cluster, mostra a tendência destes em citar os mesmos autores em suas publicações (Figura 13).

Figura 13. Rede de acoplamento bibliográfico elaborada a partir dos 37 autores participantes em no mínimo 3 dos 97 trabalhos analisados. O mapa foi elaborado no software de visualização VOSviewer a partir de dados bibliométricos extraídos de 97 artigos revisados, com a temática mamíferos como reservatórios de Trypanosoma, e indexados na Web of Science e Scopus. Utilizou-se como tipo de análise acoplamento bibliográfico e método de contagem autores.

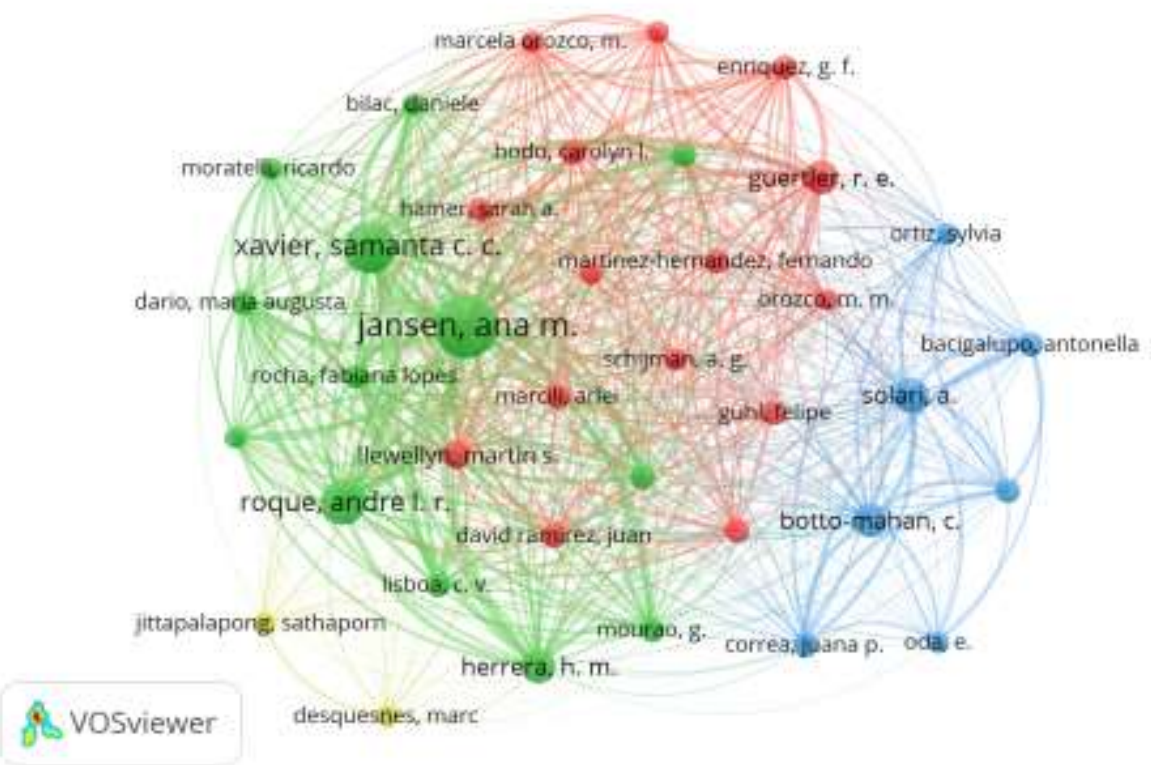

Fonte: Autores. 


\subsection{Rede de coocorrência de palavras-chave}

A rede de coocorrência de palavras-chave considerou aquelas que coocorreram em no mínimo 10 dos 97 artigos analisados, resultando em 11 palavras. Formou-se três clusters indicados pelas cores cujas linhas mostram os relacionamentos de coocorrência e o tamanho dos círculos a proporção da quantidade de vezes que uma certa palavra é listada como palavrachave nos artigos. A palavra-chave mais utilizada nos artigos analisados foi "chagas disease" que aparece em 57,73\% dos artigos, seguida por "Trypanosoma cruzi", presente em 38\% e "Transmission" em 27\%. Observa-se também que as duas palavras que mais coocorreram foram "chagas disease" e "Trypanosoma cruzi" (Figura 14).

Figura 14. Rede de coocorrência de palavras-chave elaborada com as 11 palavras mais utilizadas nos 97 trabalhos analisados. O mapa foi elaborado no software de visualização VOSviewer a partir de dados bibliométricos extraídos de 97 artigos revisados, com a temática mamíferos como reservatórios de Trypanosoma, e indexados na Web of Science e Scopus. Utilizouse como tipo de análise coocorrência e método de todas as palavras-chave.

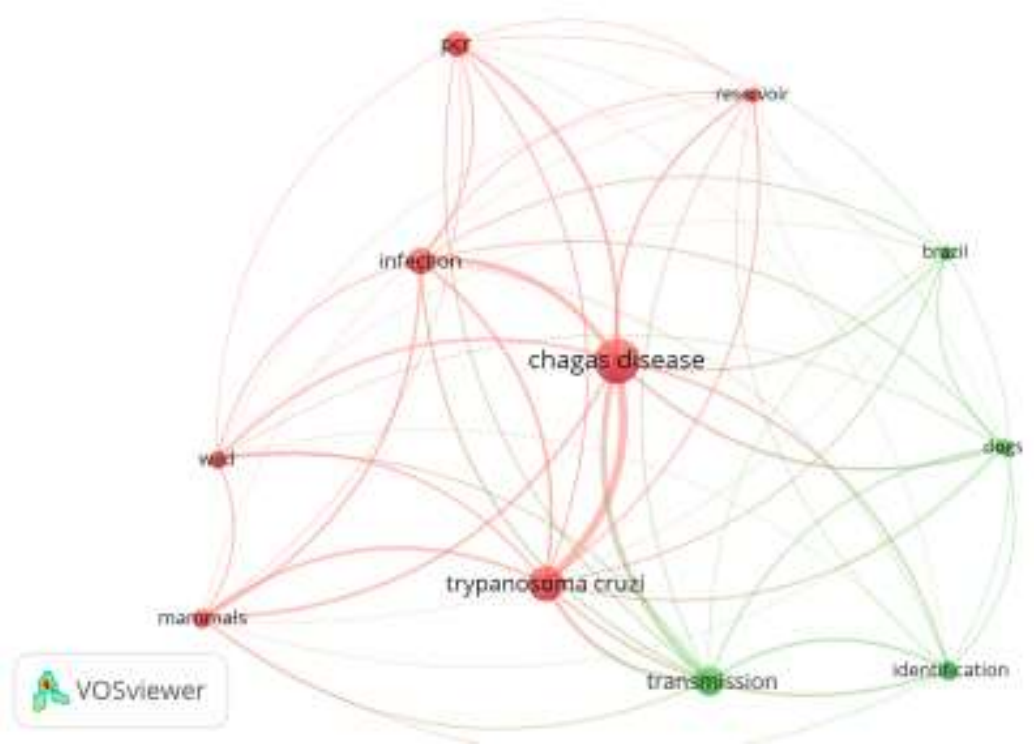

Fonte: Autores.

\section{Discussão}

A análise da produção científica em uma determinada área por meio de métodos bibliométricos permite mensurar o quanto certo tema constitui uma pergunta que intriga os cientistas bem como possibilita avaliar o quanto e como pesquisadores, instituições e países estão envolvidos na busca de respostas a esta pergunta (Macias-Chapula, 1998). Um dos primeiros aspectos a ser analisado numa análise bibliométrica refere-se à indexação dos artigos analisados, visto que o aceite das fontes de publicação nas bases, indica o reconhecimento de mérito e aval da qualidade dos artigos (Braile, et al., 2007). Desta forma, neste estudo, ao considerarmos artigos publicados em duas das mais conceituadas bases de indexação (Web of Science e Scopus), buscou-se a garantir o mérito qualitativo das produções. A sobreposição em praticamente $100 \%$ das publicações nas duas bases, selecionadas com base na temática estudada, demonstra que os artigos investigados estão de fato bem avaliados enquanto mérito científico. 


\subsection{Periódicos e temporalidade das publicações}

Embora as bases de indexação utilizadas não indexem tão somente artigos na língua inglesa (Lopes, et al., 2012) o predomínio do inglês nas publicações reforça a utilização desta língua como o idioma internacional da comunicação científica. A utilização de um idioma comumente aceito relaciona-se à premissa de que mais importante do que publicar é ser lido e ser citado (Fuza, 2017) uma vez que o cientista, por meio da publicação do conjunto de informações, visa acrescentar conhecimento à sua área (Pitrez, 2009) e portanto, publicar em uma língua comumente aceita facilita esta comunicação. Desta forma consideramos que os autores dos 97 artigos analisados neste estudo, buscaram garantir a melhor forma de acesso aos conhecimentos produzidos ao disponibilizar as publicações na língua inglesa, mesmo que esta tenha sido uma exigência dos periódicos.

A concentração de mais de $50 \%$ das publicações em $1 / 5$ das revistas em que os 97 artigos foram publicados, indica que estes constituem os principais periódicos a publicar estudos com enfoque neste tema. Esta afirmativa se reforça quando se observa a rede de relacionamento das revistas (Figura 4) em que evidencia que estas também são as revistas mais citadas nas publicações sobre o tema mamíferos como reservatórios de Trypanosoma. Esta condição indica o fator de impacto que estes periódicos apresentam e, portanto, atraem mais leitores e consequentemente mais procura para publicações elevando a quantidade e qualidade das informações disponibilizadas (Silva, et al., 2018).

A análise quantitativa de produções de artigos, dentro do tema estudado, ao apontar crescimento estatisticamente significativo ao longo dos dez anos avaliados (Figura 5), indica que a temática mamíferos como reservatórios de Trypanosoma, constitui um pergunta que ainda não se encontra totalmente respondida dentro da ciência. Da mesma forma a investigação dentro desta temática se mostra importante na busca de subsídios para controle de doenças, podendo ser considerada um hot topic.

Os principais enfoques dados pelos 97 artigos foram nas áreas de Parasitologia, Medicina Tropical e Doenças infecciosas indicando que o os estudos têm como principal enfoque a relação parasita-doenças incluindo o ser humano. De fato, as doenças parasitárias têm sido uma preocupação da Organização Mundial da Saúde (Who, 2017), dentre as quais cita a doença de chagas e doença do sono (tripanossomíase humana africana) e leishmaniose, como desafios à saúde pública.

\subsection{Origem das fontes de pesquisa e pesquisadores}

Dentre as tripanossomíases a doença de chagas, causada pelo Trypanosoma cruzi, atinge cerca de 7 milhões de pessoas em todo o mundo, principalmente em países da América Latina (Santos, et al., 2020). Estudos da Organização Mundial da Saúde (OMS) apontam ainda que o padrão da doença tem mudado da zona rural para urbana, aumentado o número de casos notificados nos Estados Unidos e Canadá bem como o registro de casos em países europeus e do Pacífico Ocidental. A tripanossomíase humana africana (doença do sono), endêmica da África, embora tenha reduzido o número de novos casos, ainda tem altos índices em alguns países, como na República Democrática do Congo (Who, 2017).

O reconhecimento por parte OMS que as tripanossomíases constituem importante problema de saúde pública, e as alterações no padrão epidemiológico destas doenças, constituem inquietações que estimulam as pesquisas. Nota-se, portanto, um incremento no número de pesquisas como mencionado anteriormente, e concentrada nos países com alta incidência destas doenças como no Brasil, Argentina, México e Estados Unidos, conforme demonstrado na Figura seis. Não apenas a fonte dos dados é oriunda destes locais, mas também os pesquisadores estão de certa forma concentrados nestes países. Porém percebese importantes interações entre pesquisadores de distintos países (Figura 7), o que reforça a importância internacional do tema bem como possibilita formação de expertises em áreas temáticas, cria novas oportunidades de investigação, possibilita a utilização de novas tecnologias e amplia a velocidade de dispersão da informação (Oliveira, 2018). 
A utilização de métodos bibliométricos constituem importantes mecanismos de mensuração da condição hot topic de determinados temas, mas permite também avaliar como um determinado país se insere no contexto da produção de conhecimento sobre este determinado tema (Macias-Chapula, 1998). Desta forma podemos perceber (Figura 7) que o Brasil se destaca no cenário internacional, quando se refere a estudos sobre o tema mamíferos como reservatório de Trypanosoma Figurando como o mais importante intermediador da pesquisa, neste tema, entre todos os países. Esta condição certamente está relacionada ao fato do Brasil ainda ser um dos países com maior índice de ocorrência da tripanossomíase americana (doença de Chagas) (Santos, et al., 2020), bem como possuir importantes centros de pesquisa com enfoque em saúde pública como a Fiocruz.

\subsection{Instituições de vínculo dos autores}

A grande quantidade de instituições (170) às quais os autores dos 97 artigos avaliados, estão relacionados, ratifica que o assunto estudado (mamíferos como reservatórios de Trypanosoma) constitui uma temática de amplo interesse. Dentre todas as instituições relacionadas destacam instituições brasileiras com pesquisas direcionadas principalmente à investigação de Trypanosoma cruzi e seus reservatórios.

A maioria das instituições são universidades e/ou centros de pesquisa que também oferecem cursos de pós-graduação, mostrando forte ligação entre processos de formação profissional e pesquisa. Dentre as instituições brasileiras destacam as públicas, como Fiocruz, USP, Embrapa, UERJ corroborando os indicadores de que a produção científica no Brasil está concentrada nas Instituições públicas (Clarivate Analytics, 2019).

A Fiocruz se apresenta com maior grau de centralidade e de intermediação entre as instituições (Figura 8), a partir da qual se tem formado pesquisadores por seus programas de pós-graduação e mantido a relação entre os orientadores e os novos pesquisadores em outras instituições. O destaque da Fiocruz nesta temática certamente está relacionado à sua vocação, desde sua criação em 1900, que é de promover a pesquisa e subsidiar a formulação de políticas e ações de saúde pública (Buss \& Gadelha, 2002). A Fiocruz é pioneira em estudos da tripanossomíase americana e desde a descoberta da relação Trypanosoma cruzi e a doença de chagas, vem realizando estudos diversos sobre a doença, constituindo um dos melhores centros mundiais de pesquisa nesta temática (Valverde, 2020).

\subsection{Rede de coautores}

Por meio da análise da rede de coautores dos artigos é possível identificar como os pesquisadores se relacionam em termos de diversidade de quantidade de interações nas publicações (Lima \& Leocádio, 2018). Por este mapa se revela uma estrutura social da produção e difusão do conhecimento da temática analisada (Acedo, et al., 2006).

No mapa de rede construído a partir dos 97 artigos avaliados com a temática mamíferos como reservatórios de Trypanosoma, se destacam pesquisadores brasileiros e com vínculos à Fiocruz. A pesquisadora Ana Maria Jansen se sobressai nas interações por participar em maior número de publicações. Percebe-se a importância da Fiocruz e da participação da autora citada na produção científica sobre o tema, visto que os outros dois pesquisadores com maiores interações, Samanta Cristina Chagas Xavier e André Luiz Rodrigues Roque (Figura 9), também possuem vínculo com a mesma instituição, tendo sido formados em nível de pós-graduação por ela e sob orientação da Dr. Ana Maria Jansen (Roque, 2021; Xavier, 2021).

Este grupo, principalmente em função da participação de Jansen, possuem interações com outras instituições nacionais como USP e Universidade Católica Dom Bosco de Mato Grosso do Sul e de outros países como Colômbia e Reino Unido. Além destes destacam outros grupos liderados por Botto-Mahan e Aldo Solari da Universidad de Chile, MartinezHernandez do México, Guertler e Enriquez da Universidad de Buenos Aires - Argentina. Como estes pesquisadores se 
relacionam com outros, ao longo da rede de interações em função de pesquisarem tema semelhante, a rede de conhecimento é gerada e transmitida de forma universal, o que é evidenciado no mapa de interações da Figura 9.

\subsection{Rede de citações e Cocitações}

A expressividade de um pesquisador em determinada área, não se dá apenas pelas pesquisas que realiza ou pelo número de artigos publicados. Sua importância se consolida na medida em que é citado por outros autores, como forma de reconhecimento e crença às abordagens dada pelo citado (Fuza, 2017). Desta forma a averiguação da rede de citações dentro de uma análise bibliométrica possibilita diagnosticar o quanto determinado autor é reconhecido por seus pares que pesquisam na mesma área (Araújo, 2006). Neste sentido, os autores brasileiros com maior participação como coautores, também se apresentam como os mais reconhecidos dentre os 474 autores listados nas 97 publicações analisadas neste estudo (Figura 10).

Quando se trata de cocitações é aferida a frequência na qual determinado autor é citado simultaneamente por mais de uma publicação posterior, indicando que estas apresentam semelhanças de ideias e que está ocorrendo a disseminação do conhecimento gerado sobre o tema (Benckendorff \& Zehrer, 2013). Neste aspecto os dois principais pesquisadores também são Brasileiros, Bianca Zingales e Arlei Marcili, ambos com vínculos com a Universidade de São Paulo, assim como a quinta mais citada Ana Maria Jansen da Fiocruz (Figuras 11 e 12).

Como observado, tanto os autores com mais publicações quanto os mais citados, dentro da temática mamíferos como reservatórios de Trypanosoma, nos últimos dez anos, são brasileiros, vinculados a instituições públicas de ensino e pesquisa (Fiocruz e USP). Esta condição reforça o importante papel do Brasil e das instituições públicas de pesquisa no cenário de investigações sobre doenças tropicais e produção de conhecimentos que subsidiam as tomadas de decisões em saúde pública.

\subsection{Rede de acoplamento bibliográfico}

A rede de acoplamento bibliográfico complementa a compreensão da rede de cocitações, indicando que quanto maior a proximidade entre dois dos autores do mapa, maior a quantidade de referências coincidentes entre eles (Palludeto \& Felipini, 2019). Desta forma fica evidenciado, que os autores mantêm uma proximidade teórica e metodológica sobre a temática explorada (Egghe \& Rousseau, 2002).

Em nossa pesquisa observou-se a estruturação da rede de acoplamento em três grupos que interagem entre si (Figura 13). A rede evidencia a forte interação entre um grupo ligado à Fiocruz, pela pesquisadora Ana Maria Jansen, Samanta Cristina Xavier e André Roque e a partir destes outros pesquisadores. Em um segundo agrupamento destacam Botto-Mahan e Aldo Solari da Universidad de Chile e num terceiro que se relaciona fortemente com os outros dois onde tem destaque Guertler e Enriquez da Universidad de Buenos Aires- Argentina. Estes agrupamentos evidenciam os núcleos de formação, a estruturação de grupos de pesquisa, as publicações em coautoria, a manutenção do foco na mesma temática de pesquisa e a forte interação entre os pesquisadores.

\subsection{Rede de coocorrência de palavras-chave}

A rede de coocorrência de palavras-chave constitui um mecanismo para compreensão da estrutura das ideias contidas nas pesquisas evidenciando a proximidade de conteúdos entre as publicações, visto que são escolhidas as principais palavras que representam os conceitos contidos na pesquisa (Egghe \& Rousseau, 2002; Souza \& Fontenele, 2019). Desta forma ao registrarmos as palavras "chagas disease", "Trypanosoma cruzi" e "transmission" como as mais frequentes e centrais fica evidenciado que a maioria das pesquisas sobre mamíferos como reservatórios de Trypanosoma, tem como foco a doença de chagas causada pelo Trypanosoma cruzi. 
O aparecimento das palavras "brazil" e "pcr", também demonstram que grande parte das pesquisas tem enfoque no Brasil e a técnica do PCR é o principal método utilizado para os diagnósticos. Além do termo "mammals" a palavra "dog" também aparece dentre as mais utilizadas, o que demonstra que muito das pesquisas avaliaram animais domésticos, além dos silvestres.

\section{Conclusão}

A temática mamíferos como reservatórios de Trypanosoma constitui um assunto recorrente na última década demonstrando ser um tema importante em saúde pública. A dedicação a um importante conjunto de estudos dentro desta temática evidencia que há uma preocupação internacional em relação a doenças parasitárias e a busca pela compreensão do ciclo ecológico das doenças ocasionadas por estes parasitas como subsídios ao seus controles.

A maioria das pesquisas, dentro desta temática, investiga Trypanosoma cruzi enquanto causador da doença de chagas. Neste cenário internacional o Brasil tem destaque que por meio da Fiocruz e USP desenvolve a maioria das pesquisas. As redes de interações evidenciam este destaque principalmente pelos graus de centralidade e de intermediação de três pesquisadores ligados à Fiocruz, Ana Maria Jansen, Samanta Cristina Xavier e André Luiz Roque e outros dois ligados à USP, Bianca Zingales e Arlei Marcili.

O aparecimento de países como Estados Unidos, França, Portugal, Espanha, Austrália e outros países asiáticos no mapa de interações de pesquisas sobre mamíferos como reservatórios de Trypanosoma, abordando principalmente T. cruzi, reforça apontamentos da Organização Mundial da Saúde quando registra ocorrência e aumento de casos de doenças de chagas nestas regiões. A interação de pesquisadores destes países com instituições latino-americanas e africanas amplia a rede de instituições e cientistas na busca por maiores conhecimentos sobre tripanossomíases e de respostas ao controle destas doenças que constituem um problema de saúde pública.

Os dados bibliométricos desta pesquisa, ao evidenciarem que o tema mamíferos como reservatórios de Trypanosoma constitui um tema de importante interesse internacional, indicam que ainda faltam muitas informações para se estabelecer mecanismos de controle das tripanossomíases. A ampliação e continuidade das redes de investigações nesta temática são fundamentais a fim consolidar subsídios e estratégias de políticas públicas de saúde.

\section{Agradecimentos}

Agradecemos a Universidade do Estado de Mato Grosso pelo apoio na realização da Pesquisa por meio do Programa de Pós-Graduação em Ciências Ambientais; à Rede Erosão da Biodiversidade, na qual esta pesquisa se insere; à Fundação de Amparo à Pesquisa do Estado de Mato Grosso (FAPEMAT) pelo apoio financeiro ao projeto "Erosão da biodiversidade no Alto Paraguai: impactos do uso do solo na estrutura da vegetação e da comunidade vertebrada terrestre e aquática" (edital $n^{\circ}$ 037/2016, Redes de Pesquisa em Mato Grosso com prazo de concessão nº 0589188/2016).

\section{Referências}

Acedo, F. J., Barroso, C., Casanueva, C., \& Galan, J. L. (2006). Co-Authorship in Management and Organizational Studies: An Empirical and Network Analysis*. Journal of Management Studies, 43 (5), 957-983. https://doi.org/10.1111/j.1467-6486.2006.00625.x

Alho, C. J. R. (2012). Importância da biodiversidade para a saúde humana: uma perspectiva ecológica. Estudos Avançados, 26 (74), $151-166$.

Araujo, A., Reinhard, K., Ferreira, L. F., Pucu, E., \& Chieffi, P. P. (2013). Paleoparasitology: the origin of human parasites. Arquivos de Neuro-Psiquiatria, 71(9B), 722-726. https://doi.org/10.1590/0004-282X20130159

Araújo, C. A. (2006). Bibliometria: evolução histórica e questões atuais. Em Questão, 12 (1), 11-32. https://seer.ufrgs.br/EmQuestao/article/view/16/5

Ávila-Pires, F. D. De. (1989). Zoonoses: hospedeiros e reservatórios. Cadernos de Saúde Pública, 5(1), 82-97. https://doi.org/10.1590/S0102$311 \mathrm{X} 1989000100007$ 
Benckendorff, P., \& Zehrer, A. (2013). A network analysis of tourism research. Annals of Tourism Research, 43 (Mci), 121-149. https://doi.org/10.1016/j.annals.2013.04.005

Borgatti, S. P., Everett, M. G., \& Freeman, L. C. (2002). Ucinet for Windows: Software for Social Network Analysis. Harvard,MA: Analytic Technologies.

Braile, D. M., Brandau, R., \& Monteiro, R. (2007). A importância da indexação para as revistas científicas. Revista Brasileira de Cardiologia Invasiva, 15 (4), 341-342. https://doi.org/10.1590/S2179-83972007000400006

Bufrem, L., \& Prates, Y. (2005). O saber científico registrado e as práticas de mensuração da informação. Ciência Da Informação, 34 (2), 9-25. https://doi.org/10.1590/S0100-19652005000200002

Buss, P. M., \& Gadelha, P. (2002). Fundação Oswaldo Cruz: experiência centenária em biologia e saúde pública. São Paulo Em Perspectiva, 16 (4), $73-83$. https://doi.org/10.1590/s0102-88392002000400012

Carvalho, M. M., Fleury, A., \& Lopes, A. P. (2013). An overview of the literature on technology roadmapping (TRM): Contributions and trends. Technological Forecasting and Social Change, 80 (7), 1418-1437. https://doi.org/10.1016/j.techfore.2012.11.008

Chen, C. (2013). Full-Text Citation Analysis : A New Method to Enhance. Journal of the American Society for Information Science and Technology, 64 (July), 1852-1863. https://doi.org/10.1002/asi

Clarivate Analytics. (2019). Research in Brazil: Funding excellence. Analysis prepared on behalf of CAPES by the Web of Science Group. Web of Science Group, 42.

Cronin, B., Shaw, D., \& La Barre, K. (2003). A cast of thousands: Coauthorship and subauthorship collaboration in the 20th century as manifested in the scholarly journal literature of psychology and philosophy. Journal of the American Society for Information Science and Technology, 54 (9), 855-871. https://doi.org/10.1002/asi.10278

Eck, N. J., \& Waltman, L. (2010). Software survey: VOSviewer, a computer program for bibliometric mapping. Scientometrics, 84 (2), $523-538$. https://doi.org/10.1007/s11192-009-0146-3

Egghe, L., \& Rousseau, R. (2002). Co-citation, bibliographic coupling and a characterization of lattice citation networks. Scientometrics, 55 (3), 349-361. https://doi.org/10.1023/A:1020458612014

Fuza, Â. F. (2017). O papel da língua inglesa na publicação acadêmico-científica: reflexões teóricas e o caso dos cursos de escrita on-line brasileiros. Signótica, 29 (2), 302-328. https://doi.org/10.5216/sig.v29i2.43926

Huang, Z. Y. X., Van Langevelde, F., Estrada-Peña, A., Suzán, G., \& De Boer, W. F. (2016). The diversity-disease relationship: evidence for and criticisms of the dilution effect. Parasitology, 143 (9), 1075-1086. https://doi.org/10.1017/S0031182016000536

Jansen, A. M., Xavier, S. C. das C., \& Roque, A. L. R. (2020). Landmarks of the Knowledge and Trypanosoma cruzi Biology in the Wild Environment. Frontiers in Cellular and Infection Microbiology, 10 (February), 1-15. https://doi.org/10.3389/fcimb.2020.00010

Jarneving, B. (2007). Bibliographic coupling and its application to research-front and other core documents. Journal of Informetrics, 1 (4), $287-307$. https://doi.org/10.1016/j.joi.2007.07.004

Lima, S. H. de O., \& Leocádio, Á. L. (2018). Mapeando a Produção Científica Internacional Sobre Inovação Aberta. Revista Brasileira de Gestão e Inovação, 5 (2), 181-208. https://doi.org/10.18226/23190639.v5n2.08

Lopes, S., Costa, M. T., Fernandéz-Llimós, F., Amante, M. J., \& Lopes, P. F. (2012). A Bibliometria e a Avaliação da Produção Científica: indicadores e ferramentas. Actas - Congresso Nacional de Bibliotecários, Arquivistas e Documentalistas, 11, 1-7.

Machado Junior, C., Souza, M. T. S., Parisotto, I. R. dos S., \& Palmisano, A. (2016). As Leis da Bibliometria em Diferentes Bases de Dados Científicos. Revista de Ciências Da Administração, 18 (44), 111-123. https://doi.org/10.5007/2175-8077.2016v18n44p111

Macias-Chapula, C. A. (1998). O papel da informetria e da cienciometria e sua perspectiva nacional e internacional. Ciência Da Informação, 27 (2), 134-140. https://doi.org/10.1590/S0100-19651998000200005

Malafaia, G., \& Rodrigues, A. S. de L. (2010). Centenário do descobrimento da doença de Chagas : desafios e perspectivas. Revista Da Sociedade Brasileira de Medicina Tropical, 43 (5), 483-485.

Microssoft Excel. (2010). Microssof excel. Computer Software.

Neves, D. P. (2005). Parasitologia Humana (11th ed.). Livraria Atheneu.

Oliveira, E. H. C. de. (2018). Redes de colaboração em pesquisa e intercâmbio de conhecimento científico. Revista Pan-Amazônica de Saúde, 9 (4), 9 -11. https://doi.org/10.5123/S2176-62232018000400001

Oliveira, E. F. T., \& Grácio, M. C. C. (2012). Visibilidade dos pesquisadores no periódico Scientometrics a partir da perspectiva brasileira: um estudo de cocitação. Em Questão, 18 (3), 99-113. https://doi.org/10.19132/1808-5245183.

Palludeto, A. W. A., \& Felipini, A. R. (2019). Panorama da literatura sobre a financeirização (1992-2017): uma abordagem bibliométrica. Economia e Sociedade, 28 (2), 313-337. https://doi.org/10.1590/1982-3533.2019v28n2art02

Pitrez, P. M. (2009). O idioma da ciência: rompendo barreiras para ser lido e citado. Scientia Medica, 19 (1), 2.

Roque, A. L. R. (2009). Avaliação do potencial de pequenos mamíferos e importância de animais domésticos na manutenção dos ciclos de transmissão de 
Research, Society and Development, v. 10, n. 7, e19710716539, 2021

(CC BY 4.0) | ISSN 2525-3409 | DOI: http://dx.doi.org/10.33448/rsd-v10i7.16539

tripanosomatídeos: Trypanosoma cruzi, Leishmania infantum e Leishmania braziliensis. Instituto Oswaldo Cruz.

Roque, A. L. R. (2021). Currículo do sistema currículo Lattes. http://lattes.cnpq.br/4648411135225077

Santos, E. F., Silva, Â. A. O., Leony, L. M., Freitas, N. E. M., Daltro, R. T., Regis-Silva, C. G., Del-Rei, R. P., Souza, W. V., Ostermayer, A. L., Costa, V. M., Silva, R. A., Ramos, A. N., Sousa, A. S., Gomes, Y. M., \& Santos, F. L. N. (2020). Acute Chagas disease in Brazil from 2001 to 2018 : A nationwide spatiotemporal analysis. PLOS Neglected Tropical Diseases, 14 (8), e0008445. https://doi.org/10.1371/journal.pntd.0008445

Santos, P. M. de S., Silva, S. G. N. da, Fonseca, C. F. da, \& Oliveira, J. B. de. (2015). Parasitos de aves e mamíferos silvestres em cativeiro no estado de Pernambuco. Pesquisa Veterinária Brasileira, 35 (9), 788-794. https://doi.org/10.1590/S0100-736X2015000900004

Silva, D. D., Almeida, C. C., \& Grácio, M. C. C. (2018). Associação do Fator de Impacto e do Índice h para a avaliação de periódicos científicos: uma aplicação no campo da Ciência da Informação. Em Questão, 24 (Edição especial 6 EBBC), 132-151. https://doi.org/10.19132/1808-5245240.132-151

Souza, E. S., \& Fontenele, R. E. S. (2019). Mapeamento da produção científica internacional sobre Valores Humanos Básicos. Em Questão, 25 (3), $214-245$. https://doi.org/10.19132/1808-5245253.214-245

Valverde, R. (2020). Dia Mundial de Doença de Chagas mostra protagonismo da Fiocruz. Fiocruz. https://agencia.fiocruz.br/dia-mundial-de-doenca-dechagas-mostra-protagonismo-da-fiocruz

Wallin, J. A. (2005). Bibliometric Methods: Pitfalls and Possibilities. Pharmacology \& Toxicology, 97 (5), 261-275. https://doi.org/10.1111/j.17427843.2005.pto_139.x

Wilkinson, L. (1998). Systat the system for statistics.SYSTAT inc. Illinois.

World Health Organization (WHO). (2017). Integrating neglected tropical diseases into global health and development: fourth WHO report on neglected tropical diseases. In World Health Organization. World Health Organization (WHO). https://unitingtocombatntds.org/wpcontent/\%0Auploads/2017/11/4th_who_ntd_report.pdf

Xavier, S. C. das C. (2021). Currículo do sistema currículo Lattes. http://lattes.cnpq.br/4527212372960718 